\title{
Contacto y cambios lingüísticos en el pasado: sobre las sibilantes castellanas en el Bilbao del siglo XVII
}

\section{Contact and Linguistic Changes in the Past: About the Spanish Sibilants in the $17^{\text {th }}$ Century Bilbao}

\author{
Eneko Zuloaga \\ Universidad del País Vasco (UPv/EHu) \\ eneko.zuloaga@ehu.eus
}

Resumen

El presente trabajo ahonda en el estudio de la transición del sistema fonológico castellano medieval al moderno: se trabaja en la descripción del sistema de sibilantes castellanas del siglo Xvir en el área de Bilbao, territorio bilingüe vasco-castellano al norte de la Península Ibérica. Para dicho fin se ha analizado el manuscrito de Rafael de Micoleta (1653). En concreto, se pretende dilucidar en qué estado se hallaban los procesos de fricatización y ensordecimiento en el norte peninsular, y la existencia de la interdental $/ \theta /$, nueva en aquella época. Se estudia, además, la presencia del seseo, así como su relación distributiva con la / $\theta$ / y la posible influencia del contacto lingüístico vasco-castellano en su creación y desarrollo.

En resumen, se describe un estado avanzado para las neutralizaciones mencionadas y se defiende, sin embargo, la inexistencia de la interdental $/ \theta /$ en el Bilbao de la época, al menos de forma extendida, debido a la existencia bien documentada del seseo. Además, se suma el argumento de la cronología absoluta para descartar una posible influencia de las neutralizaciones ocurridas en lengua vasca en el origen del seseo, si bien dicha influencia no se descarta para épocas y procesos posteriores.

Palabras Clave: castellano del País Vasco, grafemática, fonética, fonología, sibilantes, seseo, contacto vasco-románico

\section{Abstract}

The purpose of this paper is to offer a thorough analysis of the transition between the phonological systems of Mediaeval and Modern Castilian. The goal is to describe the sibilant system of $17^{\text {th }}$ century Bilbao Castilian, i.e. a variety spoken in a bilingual (Basque-Castilian) area in the north of the Iberian Peninsula. For that purpose, the manuscript of Rafael de Micoleta (1653) was chosen as the central area of study. I discuss to what extent the neutralizations between the voiced/voiceless and fricative/affricate sibilant contrasts were completed, as well as how $/ \theta /$, new at that time, was extended. Furthermore, I study the presence of the seseo, its distributional relationship with $/ \theta /$, and the possible influence of Basque-Romance contact in both its origin and development.

I argue that the aforementioned neutralizations were quite advanced in the 17 th century. However, I defend that $17^{\text {th }}$ century Bilbao Castilian lacked the interdental $/ \theta /$, at least 
as a widespread pronunciation. In addition, I argue that any influence of the neutralizations occurred in Basque has to be ruled out as an explanation of the origin of the Castilian seseo, even though this influence cannot be discarded for subsequent periods.

KeYwords: Castilian of the Basque Country, graphemics, phonetics, phonology, sibilants, seseo, Basque-Romance contact

FECHA DE RECEPCIÓN: 16/10/2018

FECHA DE ACEPTACIÓN: 11/03/2019

\section{Introducción ${ }^{1}$}

1.1. Este artículo pretende arrojar algo de luz sobre un tema complejo: la descripción del sistema fonológico castellano del área históricamente vascófona y, más concretamente, del área de Bilbao, en el País Vasco meridional. La complejidad del tema reside entre otros en el gran número de aspectos y variables a considerar necesariamente para una reconstrucción fiable del pasado lingüístico: la falta de información precisa sobre el ecosistema lingüístico de la época, los límites derivados del propio corpus, los problemas inherentes a los estudios del ámbito de la grafemática, la existencia de inestabilidad y variación grafofonológica tanto en lengua castellana como en lengua vasca, la posible pero no del todo clara influencia del contacto lingüístico

\footnotetext{
${ }^{1}$ El presente trabajo se inscribe dentro del proyecto de investigación "Monumenta Linguae Vasconum (V): periodización y cronología” [código FFI2016-76032-P], financiado por el Ministerio de Economía y Competitividad del Gobierno de España, y del grupo de investigación consolidado "Lingüística histórica e historia de la lengua vasca” [GIC0/83 IT1344-19] financiado por el Gobierno Vasco. Una primera versión del trabajo fue presentada en las VII Jornadas Internacionales de Lingüística Hispánica. Lengua y sociedad (Universidade de Lisboa, 16-18 de abril de 2018): quisiera agradecer al profesor Bruno Camus (Universidad de Castilla la Mancha) el interés mostrado y los comentarios realizados tras la comunicación; asimismo, quisiera agradecer a los profesores José Ignacio Hualde (University of Illinois) y Ekaitz Santazilia (Universidad Pública de Navarra) los comentarios realizados tras leer una primera versión del texto. Huelga decir que las opiniones y los posibles errores son asumidos plenamente por el autor.
} 
vasco-castellano en algunos procesos, etcétera. La complejidad del tema y la incertidumbre con la que los investigadores han solido moverse en el estudio de la "revolución" fonética y fonológica del castellano de los siglos XVI y XVII queda magníficamente sintetizada en la siguiente cita:

La revolución fonética y fonológica del siglo xvi es un hecho constantemente estudiado por los investigadores de la lingüística histórica, pero no por ello totalmente clarificado. Los puntos oscuros son muy abundantes y más numerosos cuanto más avanza la investigación. Los cambios fonéticos que provocaron la revolución del sistema fonológico del castellano se produjeron con distinta intensidad y en fechas diferentes en las diversas comarcas castellanohablantes; de modo que generalizar y dar una única respuesta para explicar estos hechos no será más que una simplificación de la cuestión con la consiguiente imprecisión y falta de rigor científico. El conocimiento total y verdadero de este problema lo obtendremos sólo cuando dispongamos de suficientes estudios parciales que saquen a la luz cómo se produjeron estos cambios en los distintos lugares del dominio hispánico (Satorre, 1989: 267).

1.2. El objeto de estudio que nos ocupa es la transición del sistema de sibilantes medieval al moderno en el castellano del área de Bilbao, y surgió en realidad de la necesidad de ofrecer algunas aclaraciones dentro del ámbito de la historia de la lengua vasca o euskera.

Los dialectos vascos centrales y orientales mantienen un sistema de sibilantes moderadamente complejo (Igartua y Zabalza, 2012: 11) compuesto por dos fricativas sordas (predorsoalveolar y apicoalveolar, expresadas hoy en día mediante los grafemas $\langle\mathrm{z}\rangle \mathrm{y}<\mathrm{s}\rangle$ ) y dos africadas con idénticos puntos de articulación ( $<\mathrm{tz}>\mathrm{y}<\mathrm{ts}>$ en grafía actual). Se trata, en lo fundamental, de los mismos componentes del sistema propuesto por Michelena $(1957,1961)$ para el protovasco ${ }^{2}$ al que hay que aña-

\footnotetext{
${ }^{2}$ Históricamente hallamos fricativas en posición inicial, tendencia a la africada al final del tema, pronunciación fricativa ante oclusiva y neutralización de la oposición fricativa/africada tras $l, n$ y, en menor grado, $r$ (Michelena, 1961: \$14).
} 
dir sendos fonemas prepalatales fricativo y africado (expresados hoy en día mediante $<\mathrm{x}>\mathrm{y}<\mathrm{tx}>$ ) presentes en todos los dialectos y asociados históricamente a variantes afectivas (Trask, 1997: $\$ 3.4$; Egurtzegi, 2013: $\$ 4.4 .3 .3$ y $\$ 4.4 .4 .1$ ).

Frente a las áreas conservadoras central y oriental del País Vasco, en la zona occidental se han producido dos neutralizaciones a lo largo de los últimos siglos: la fricativa predorsoalveolar se ha asimilado a la fricativa apicoalveolar y la africada apicoalveolar ha pasado a realizarse como africada predorsoalveolar. ${ }^{3}$

En el plano cronológico, la neutralización de las fricativas se documenta en textos occidentales y centrales del siglo XVI principalmente ante oclusiva, extendiéndose en la zona occidental (Señorío de Bizkaia, tierras alavesas y costa y valles occidentales guipuzcoanos) a las restantes posiciones a partir de entonces. Asimismo, la neutralización entre las africadas se documenta a partir del siglo XVII en el mismo territorio.

\begin{tabular}{|c|c|c|}
\hline & Sistema vasco común & Sistema reducido \\
\hline \multirow{3}{*}{ Fricativas sordas } & {$[\mathrm{s}]$} & {$[\mathrm{s}]$} \\
& {$[\mathrm{s}]$} & {$[\mathrm{S}]$} \\
& {$[\mathrm{S}]$} & \\
\hline \multirow{3}{*}{ Africadas sordas } & {$[\mathrm{ts}]$} & {$[\mathrm{ts}]$} \\
& {$[\mathrm{ts}]$} & {$[\mathrm{t}]$} \\
\hline
\end{tabular}

Cuadro 1. Inventario y reducción del sistema de sibilantes vasco común

1.3. Entre los textos vascos antiguos resulta llamativo el manuscrito de Rafael de Micoleta ( $\$ 2)$, texto bilingüe vasco-castellano fechado en 1653, en el que son evidentes y ciertamente llamativas la poligrafía y la polifonía, ${ }^{4}$ la falta de norma gráfica aparente en la expresión/diferenciación de las sibilantes y el uso

\footnotetext{
${ }^{3}$ Los procesos arriba descritos conforman lo que podríamos llamar "neutralización clásica”, que parece ser la más antigua y extendida en el área occidental del País Vasco. Sobre otras neutralizaciones locales surgidas en las series de sibilantes, véanse los trabajos de Hualde $(2000,2010)$.

${ }^{4}$ Entendidas consecutivamente como el uso de un grupo de grafías como correlato de un único fonema y como el uso de una única grafía para representar varios sonidos (Oyosa, 2013: 287).
} 
aparentemente indiscriminado de $<\mathrm{s}>$ para expresar cualquier sibilante en euskera (predorsoalveolar o apicoalveolar, fricativa $\mathrm{o}$ africada en cualquier posición), salvo las prepalatales. A la vista de dicha situación, los vascólogos (Michelena, 1961; Pagola, 2002; Hualde, 2010; Atutxa, 2013; Atutxa y Zuloaga, 2014) han solido asumir que las neutralizaciones descritas anteriormente se hallaban ya consumadas en Bilbao a mediados del siglo XVII, proponiendo que Bilbao fue el foco irradiador de la innovación.

1.4. Los efectos de la falta de una descripción y normativización lingüística para la lengua vasca escrita hasta época muy tardía ${ }^{5}$ son bien conocidos por los filólogos e historiadores del euskera, que deben analizar irremediablemente texto a texto las elecciones gráficas realizadas por cada autor. A pesar de ello, apenas existen estudios sobre temas fundamentales como las tradiciones gráficas, el conocimiento ortográfico y lingüístico de los autores meridionales, y sus preferencias y elecciones. En casos como el de Micoleta, el autor ha llegado a ser tildado de "incoherente", "despistado", "incorrecto" e "inseguro" (Pagola, 2002: 202). Sin embargo:

La variabilidad no significa, como a veces se ha dicho, anarquía o desbarajuste, ni implica necesariamente la idea de un copista ignorante que comete errores, siempre inevitables evidentemente, sino ante todo refleja el proceder de quien actúa de acuerdo a una tradición escriptológica heredada (Cabrera, 2003: 163).

La falta de una norma ortográfica vasca comúnmente aceptada y establecida a través de la tradición escrita hasta épocas muy tardías (en algunos ámbitos, en el siglo xx) obligó irremediablemente a los autores meridionales ${ }^{6}$ de épocas anteriores a

\footnotetext{
${ }^{5}$ Pese a existir notas, manuscritos y obras de menor entidad en siglos anteriores (entre otros, el de Micoleta aquí tratado), en el País Vasco meridional hubo que esperar a las obras de Manuel Larramendi, El imposible vencido. Arte de la lengua vascongada (1729) y Diccionario trilingüe del castellano, vascuence y latín (1745), gramática y diccionario respectivamente.

${ }^{6}$ La tradición septentrional ha diferenciado generalmente las fricativas y las africadas
} 
utilizar los conocimientos adquiridos en y para otras lenguas (latín y/o castellano), a pesar de resultar sistemas defectivos para expresar una correlación única e inequívoca entre fonemas y grafemas en euskera. Si bien la mayoría de textos vascos meridionales muestran los grafemas $\langle\mathrm{c}\rangle,\langle$ ç $\rangle$ y $\langle\mathrm{z}\rangle$ castellanos para expresar la fricativa predorsoalveolar $\mathrm{y}<\mathrm{s}>\mathrm{o}<\mathrm{ss}>$ para la fricativa apicoalveolar (la distinción entre fricativas y africadas no llegó a sistematizarse entre algunos autores hasta mediados del siglo XVIII, cuando añadieron una $<\mathrm{t}>$ para diferenciar las africadas $-<$ tç $>,\langle$ ts $>$, etcétera -$),{ }^{7}$ la poligrafía y la polifonía atestiguada en algunos documentos revelan diversidad en las tradiciones y en los usos gráficos.

A pesar de todo ello, a la hora de estudiar los problemas grafofonológicos en lengua vasca, son prácticamente inexistentes los trabajos que toman en consideración las tradiciones gráficas castellanas, el sistema fonológico subyacente de cada época y su posible influencia en los textos vascos. Llegados a este punto, conviene destacar la necesidad de superar la correlación automática y unívoca entre grafemas y fonemas: es evidente que los cambios fonéticos pueden originar cambios fonológicos y gráficos; sin embargo, "la aparente inestabilidad del uso gráfico no necesariamente está vinculada con una variación fonética, puede deberse, en cambio, a distintas normas gráficas" (Oyosa, 2013: 294). Será el estudio grafemático exhaustivo de un texto dado el que permita hallar resquicios para la identificación de cambios lingüísticos subyacentes más allá de la variación gráfica: "es tarea del investigador depurar los datos, con el fin de detectar las grafías que estén vinculadas con una tradición escrituraria, de aquellas que caracterizan los rasgos de una lengua,

\footnotetext{
ya desde los primeros textos del siglo xvi; véanse las aportaciones de Pikabea (1993) y Mujika (2002) sobre el tema.

${ }^{7}$ La única propuesta anterior al siglo XIx que logró cierto éxito fue formulada por Manuel Larramendi a mediados del siglo XviII y estableció, entre otros, la necesidad de diferenciar las sibilantes fricativas y africadas (véase Lakarra, 1985). Sin embargo, la "norma" larramendiana no fue conocida o aplicada sistemáticamente por todos los autores posteriores.
} 
o bien, las variaciones que sí están presentes en un determinado territorio" (Oyosa, 2013: 294).

1.5. Retomando el caso del uso "indiscriminado" de $<\mathrm{s}>$ por $\mathrm{Mi}$ coleta, Ulibarri ha puesto el foco de atención precisamente en un posible problema gráfico. Según su propuesta, el manuscrito de Micoleta no reflejaría una neutralización muy avanzada o completa a favor de la fricativa apicoalveolar, sino un problema gráfico "mal resuelto" ante la defectividad de la grafía castellana para expresar las sibilantes vascas. Argumenta así (la traducción es nuestra):

El castellano de aquella época solo contaba con una sibilante; es decir, /ś/ (grafía <s, ss >): las antiguas /s/ y /ts/ se habían convertido en $/ \theta /$ para comienzos del siglo XVII y, por lo tanto, las grafías $\langle z, c ̧, c\rangle$ expresaban ese nuevo sonido [...]. El uso generalizado de $<$ s $>$ puede comprenderse de la siguiente forma: los autores de los siglos xviI y XVIII de los que hablo únicamente tenían un grafema para expresar las sibilantes vascas, es decir, <s> (2015: 137).

La explicación resulta interesante y pertinente, y viene a proponer que los procesos de ensordecimiento y fricatización se habían completado, así como que la interdental $/ \theta /$ se había extendido y sistematizado ampliamente (al menos, lo suficiente como para reservarle en exclusividad una serie de grafemas); sin embargo, la hipótesis no viene refutada por análisis documental alguno por lo que respecta a Micoleta o a otros textos del siglo XVII. ${ }^{8}$

En el presente trabajo me centraré en el estudio del castellano, dejando el análisis y las conclusiones referidas al ámbito vasco para otra ocasión, dado el espacio excesivo que se requeriría aquí para un análisis exhaustivo del mismo. En concreto, analizaré la variación atestiguada en el texto e intentaré dilucidar hasta qué punto responde únicamente al plano gráfico y hasta qué

\footnotetext{
${ }^{8}$ A decir verdad, Ulibarri (2015) parte del análisis de una interesantísima colección de sermones de finales del siglo XVIII ( $c a .1780$ ), época y texto para el que su explicación sería válida.
} 
punto puede divisarse el sistema fonológico subyacente. Asimismo, analizaré la presencia de grafías que puedan reflejar seseo y la compatibilidad de dicho fenómeno con la $/ \theta /$ interdental.

\section{La fuente: el manuscrito de Rafael de Micoleta}

2.1. El Modo breve de aprender la lengua vizcayna redactado en 1653 por Rafael de Micoleta (1611-?), presbítero y prior del cabildo eclesiástico en Bilbao, es una fuente de sumo interés para el estudio de las lenguas vasca y castellana del Bilbao del siglo XVII, aunque el texto ha suscitado más interés entre vascólogos que entre hispanistas. Se trata de un manuscrito de 15 folios escritos por recto y verso en el que se ofrecen nociones para el aprendizaje de la lengua vasca partiendo del castellano.

Desde su descubrimiento, a finales del siglo XIX, se ha especulado con la posibilidad de que el texto se preparase para alguno de los comerciantes ingleses que visitaban asiduamente tierras vizcaínas, hecho que explicaría mejor cómo llegó hasta su único repositorio oficial conocido: el fondo donado por Robert Harley a la biblioteca del Museo Británico de Londres, donde aún se conserva. ${ }^{9}$ De cualquier modo, parece que la historia del texto guarda relación directa con el estudioso Sir Thomas Browne (familiar de R. Harley). Así lo revela una carta dirigida por Samuel Sainthill a Browne en 1661, en la que se indica que Sainthill ha llevado el manuscrito de Micoleta desde Bilbao; además, el texto de Micoleta es mencionado en la obra del propio Browne; véanse algunos detalles en Dodgson (1908).

2.2. A pesar de haber sido redactado a mediados del siglo XVII, no parece que los vascólogos de los siglos XVIII y de gran parte del xix lo conocieran o tuvieran acceso al mismo (hecho por otra parte fácilmente explicable si el manuscrito permaneció en manos privadas y fue llevado a Inglaterra poco después de escri-

\footnotetext{
${ }^{9}$ Le corresponde la siguiente signatura: [Harl. 6.314//Brit. Mus.//R. de Micoleta. Biscayan Grammar and Dialogues].
} 
birse), ya que no existe mención alguna en sus trabajos; véanse, por ejemplo, las fuentes del diccionario de Larramendi (1745) analizadas en Urgell (2005).

El texto de Micoleta permaneció inédito hasta finales del siglo XIX, cuando el historiador Salvador Sanpere i Miquel (1880) lo publicó por primera vez en la Revista de ciencias históricas y lo reeditó un año después. Una década más tarde, el investigador Edward Spencer Dodgson (1897) corrigió algunos errores de la primera transcripción y publicó una segunda versión en Sevilla. Ya durante la segunda mitad del siglo xx partes de la obra han sido editadas en diversas compilaciones de textos vascos (Michelena, 1964; Sarasola, 1983), y Zelaieta $(1988,1995)$ ofreció una nueva transcripción del texto completo.

2.3. El aspecto físico del manuscrito es de plena pulcritud: se trata de un texto muy cuidado que se asimila a una versión pasada a limpio por un amanuense; así lo demuestran, entre otros, la disposición simétrica y calculada de los apartados; la elegancia de la decoración de títulos, letras capitales, etcétera; y la fineza con la que se realizaron pequeñas correcciones, casi inapreciables a primera vista (en algún caso, incluso parece que ciertas correcciones no se llevaron a cabo por no "estropear" el texto).

Teniendo en cuenta lo anterior, cabría preguntarse si el manuscrito que nos ha llegado no es sino una versión a limpio dispuesta para su publicación, aunque la entidad relativamente menor del texto parece apuntar más a su posible preparación para el uso privado. Se trata, en cualquier caso, de un texto semiformal: no de un documento oficial o de valor legal ni administrativo, ni tampoco parece que fuese a publicarse o exponerse más allá del ámbito privado. Respecto al contenido, el ámbito más formal está conformado por los apartados gramatical y léxico, a los que se contraponen los textos literarios utilizados como muestras de la lengua (poesía amorosa y diálogos cómicos).

2.4. El contenido del Modo breve... puede dividirse en tres apartados principales. En el primero se exponen nociones gramaticales; en concreto, sobre la morfología nominal y la conjugación verbal. En el segundo se ofrece un diccionario organizado en 
orden alfabético de unas 700 palabras usuales en lengua vasca, partiendo de la entrada en castellano. El tercer apartado reúne textos que sirven de muestra de la lengua: en primer lugar, tras una breve exposición sobre los tipos de poesía vasca de la época, se muestran algunos ejemplos; en segundo lugar, Micoleta adecuó una serie de diálogos cómicos: aunque durante algún tiempo se pensó que podría tratarse de diálogos originales creados por él mismo, sabemos que el bilbaíno utilizó la obra Pleasant and Delightfull Dialogves in Spanish and English (1599) de John Minsheu, trabajo de carácter didáctico preparado para aprender castellano a partir del inglés; véase una edición crítica en Cid (1997).

2.5. En el ámbito de la vascología, el manuscrito ha sido apreciado debido a la tipología y temática del texto: se trata de una de las pocas fuentes de carácter no religioso anteriores al siglo XIX, y uno de los pocos y más antiguos textos bilingües de la zona occidental del territorio vasco. Dentro de los estudios hispánicos, el manuscrito ha sido mencionado y explotado puntualmente en algunas investigaciones sobre el castellano antiguo de la zona de Bilbao (Bizcarrondo, 2002; Hualde, 2010), aunque numerosos aspectos no han sido todavía analizados.

\section{Del castellano medieval al castellano moderno}

\subsection{La revolución fonológica}

3.1.1. Tras más de un siglo de estudios sobre el tema, puede afirmarse que la evolución del sistema de sibilantes castellanas es uno de los que más interés ha suscitado dentro de la historia de la lengua española (Oyosa, 2007: 25). A su vez, sin embargo, también constituye uno de los temas más debatidos y únicamente resuelto en parte, como indicó Malkiel (1971: 1) hace algunas décadas. En concreto, me refiero a los procesos fonológicos desarrollados durante los siglos XVI y XVII que dieron lugar a la "revolución fonológica" que marcó la transición entre los sistemas medieval y moderno. 
Es de común conocimiento entre los hispanistas que durante los siglos precedentes a la mencionada revolución el sistema de sibilantes castellanas era más complejo que el moderno; en concreto, existieron sibilantes sordas y sonoras, así como fricativas y africadas. Sin embargo, tras la época medieval se iniciaron tres procesos: ${ }^{10}$ por un lado, se perdió la distinción entre sordas y sonoras a favor de las primeras; por otro lado, las africadas se debilitaron y se convirtieron en fricativas; además, el punto de articulación de la predorsodental sorda se adelantó para evitar la homofonía y se creó el fonema interdental $/ \theta /$. Asimismo, el punto de articulación de la prepalatal se adelantó y velarizó. He aquí un resumen esquemático de los tres procesos:

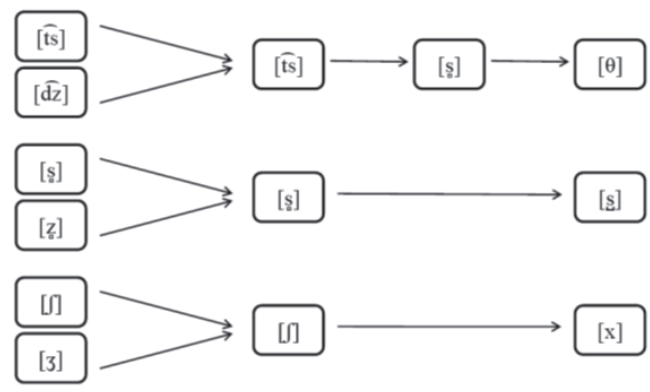

Cuadro 2. Cambios fonológicos del castellano medieval al moderno

Los procesos mencionados suelen circunscribirse a la época del Siglo de Oro español y son comúnmente aceptados como

${ }_{10}$ No todos los hispanistas coinciden al establecer una cronología relativa de los procesos: "La relación cronológica entre fricatización y ensordecimiento en estas sibilantes dentales resulta casi imposible de definir: la fechación tardía del ensordecimiento, al modo de A. Alonso, hacía suponer anterior la fricatización. Hoy, al haber adelantado el inicio del ensordecimiento, la situación se presenta mucho menos clara. Quizá, como señala Ariza (1994: 225) «en unas zonas fuese antes la fricatización y en otras el ensordecimiento». De todos modos, ambos fenómenos no se necesitan mutuamente para producirse" (Cano, 2004: 838). De cualquier modo, desde el punto de vista de la fonología natural se explicaría más fácilmente un orden del tipo (1) fricatización, (2) ensordecimiento a la manera de Alonso; véase el trabajo de Pensado (1983) sobre el orden de los procesos fonológicos, donde se trabaja desde la perspectiva de la fonología natural. 
descripciones o patrones generales, aunque muchos de los autores clásicos que se han ocupado del asunto no siempre hayan tomado en cuenta los testimonios documentales (Oyosa, 2007: 25).

Huelga decir que establecer la cronología y extensión más precisa posible de los fenómenos resulta fundamental para obtener una perspectiva general fidedigna; sin embargo, aun aceptando la descripción de los procesos, el análisis de los testimonios documentales revela continuamente una realidad compleja, heterogénea y diversa que obliga al investigador a trabajar fuente a fuente antes de poder formular generalización alguna. El filólogo debe trabajar con la mayor precisión posible en el análisis de la variación grafofonológica atestiguada, y aun así no es siempre posible deshacerse de una vaga sensación de imprecisión derivada de la parcialidad de los estudios realizados.

\subsubsection{Las investigaciones sobre la revolución fonológica moder-} na coinciden: los testimonios más fidedignos sobre el desarrollo y la extensión de los cambios son los descritos por los gramáticos de la época, aunque los datos no sean siempre tan precisos como el investigador actual quisiera. Por lo que respecta a $/ \theta /$, es cierto que algún gramático de finales del siglo XVI menciona la pronunciación interdental, nueva en aquella época; sin embargo, no parece que se trate de una innovación extendida rápidamente en la zona septentrional de la Península Ibérica, ya que las referencias a esta son escasas aún en los tratados del siglo XVII: ${ }^{11}$

Los testimonios de los gramáticos nos permiten concluir que el paso del "siseo" primitivo (fricación alargada y acanalada) al "ciceo" posterior (fricación plena transversal), aunque iniciado hacia finales del

\footnotetext{
${ }^{11}$ De los diecinueve gramáticos de los siglos XV, XVI y xvi analizados por Blanco (2006: 60) solo dos mencionan de forma más o menos clara la pronunciación $/ \theta /$ : Cuesta, en 1589, y Bonet, en 1620. Por su parte, Cano (2004: 843) cree fidedignos, además de los testimonios de los autores mencionados, los de Corro (1560), López de Velasco (1578) y Oudin (1619). En contra del consenso general, algún autor ha creído ver una mayor extensión de la sibilante interdental ya en época antigua; cf. Guitarte (1992a, 1992b).
} 
siglo XVI, no se cumplió rápidamente después, y en el siglo XVII era aún un fenómeno poco extendido y estaba todavía lejos del ceceo pleno moderno (Blanco, 2006: 84).

Respecto a los procesos de interdentalización y velarización experimentados por las antiguas sibilantes, los datos que arroja nuestro corpus confirman la visión de los hechos defendida desde la tradición hispana, que define uno y otro fenómeno como procesos tardíos que no se generalizaron hasta la segunda mitad del siglo XVII o incluso más tarde. De acuerdo con nuestros datos, parece que dichos fenómenos debieron de iniciarse hacia finales del siglo XvI y que su generalización no se consumó hasta bien entrado el siglo XVII (Blanco, 2006: 110).

[...] los siglos XVI y XVII marcarían la transición entre distintas situaciones de variación, las típicamente medievales y las modernas, más que la consecución de una situación de estabilidad y "fijación" del sistema (Cano, 2004: 825).

Al hablar de la "tradición hispana", Blanco se refiere a las opiniones vertidas por algunos de los principales hispanistas a lo largo del siglo xx acerca de la cronología de los cambios fonológicos analizados:

Por lo que se refiere al fenómeno de interdentalización, Lapesa (1942, \$924) sostiene, a la luz de los testimonios de los tratadistas, que ya en la segunda mitad del siglo xvi la articulación interdental era practicada por los hablantes del área septentrional, mientras que en Toledo y en otras zonas la igualación de $/ \theta /$ de las antiguas africadas no fue completa hasta el primer tercio del siglo XviI. A. Alonso (1955: 336 y 337), ante la falta de testimonios suficientes, sólo se atreve a conjeturar que el ciceo completo se debió de generalizar en castellano hacia la mitad del siglo xviII, aunque ya desde mediados del siglo XVI se pueden rastrear los primeros indicios de un ciceo incipiente. Para Alarcos (1950: 272-73) la interdentalización de /ş/ fue un proceso definitivamente cumplido muy tarde, aproximadamente hacia la segunda mitad entrada del siglo xvir. De modo similar, Lloyd (1987: 531-43) señala que, aunque desde los primeros años 
del siglo Xvi hay ya indicios de una incipiente pronunciación interdental del sonido escrito con $\langle$ ç>, tal y como se desprende de las descripciones articulatorias de algunos gramáticos, la generalización de este proceso llevó tiempo y no se consolidó hasta bastante tarde, probablemente a principios del siglo xvirI. También Cano (1988: 240) apunta que, aunque los primeros datos de la interdentalización de /ş/ son de la segunda mitad del siglo XVI, el fenómeno no debió de consolidarse hasta finales del siglo xviı, o incluso principios del XVIII (2006: 110-111).

La distribución social y geográfica de los fenómenos también ha solido emplearse como criterio para el análisis. Como señala Cano:

Para la correspondencia entre la variación lingüística (distinguir vs no distinguir estos fonemas) y la "externa”, existen dos indicios: uno, la defensa de la distinción [sorda/sonora], incluso cuando ya no era viva y sólo se aplicaba a la escritura, muestra que esta era la variante "culta", sociolingüísticamente "alta"; pero la indistinción no llega a calificarse de "baja" o "inculta”. El otro es la ubicación geográfica de una y otra normas que la lingüística histórica hispánica ha venido repartiendo, la igualación para Castilla la Vieja (posible área inicial), Aragón y, más dudosamente, León; y la distinción para Toledo, guía del idioma en la época, y con ella el sur peninsular, en especial Andalucía (2004: 835-836).

Es generalmente aceptado que la distribución diatópica de los cambios es horizontal: el norte peninsular, innovador; el sur, conservador. ${ }^{12}$ Como se explicita en la cita anterior, "Castilla la Vieja"13 ha sido considerada foco innovador junto a

\footnotetext{
${ }^{12}$ Aun así, Frago $(1977,1981,1985)$ ha rechazado en más de una ocasión la propagación unidireccional norte > sur, al haber hallado ejemplos de fenómenos supuestamente septentrionales en documentos andaluces.

${ }^{13}$ Dependiendo de la época histórica, las fronteras político-administrativas de Castilla la Vieja varían. De no tener en cuenta la historia del territorio, el peligro de caer en anacronismos es elevado, al poderse utilizar la misma denominación para referirse al antiguo Reino de Castilla, a los territorios gobernados bajo la Corona de Castilla
} 
Aragón ${ }^{14}$ y tal vez León. Sin embargo, no resulta fácil determinar hasta dónde se extendía "Castilla la Vieja lingüística" en el pasado; asimismo, la relación lingüística entre las tierras castellanas y vascas requiere estudios específicos: a pesar de las notas ofrecidas por algunos historiadores y de testimonios indirectos, en la actualidad está por precisarse incluso hasta dónde se extendía la zona de contacto vasco-románico en los siglos XVI y XVII y qué distribución diastrática existía entre una y otra.

Es razonable pensar, por simple proximidad geográfica, que el castellano de Bilbao estaba más próximo del de Castilla la Vieja que del de Toledo. ${ }^{15}$ Aun así, están por determinar las fronteras lingüísticas castellanas ${ }^{16}$ y la extensión de la $/ \theta /$ durante los siglos XVI y XVII, teniendo en cuenta, además, que dentro del área innovadora existieron espacios conservadores como la zona occidental de Salamanca y Asturias, Sanabria y Cáceres (Cano, 2004: 836).

Respecto a las tierras vascas, antes de afirmar nada con rotundidad deben estudiarse en detalle desde los puntos de vista gráfico y fonético-fonológico los sistemas de sibilantes atestiguados en los textos castellanos. Hasta que dicha tarea sea llevada a cabo, la perspectiva general seguirá siendo irremediablemente imprecisa: "los datos sobre el castellano de área vasca occidental siguen siendo una ausencia notable en las reconstrucciones diacrónicas del complejo castellano" (Isasi, 2006: 531).

\subsection{Una innovación del País Vasco meridional: el seseo vasco}

3.2.1. Junto a los procesos mencionados en el apartado anterior, otro fenómeno debe tomarse en consideración al trabajar con

o la distribución administrativa posterior a 1833. Asimismo, debería determinarse en qué medida puede tomarse Castilla la Vieja como entidad lingüística uniforme.

${ }^{14}$ Líbano (1998: 141 y 148) ha descrito diferencias significantes entre los testimonios de amanuenses aragoneses y navarros.

${ }^{15}$ Tras analizar diversos textos vascos occidentales del siglo xvi, Hualde (2010: 102 y siguientes) ha determinado que la distinción entre sordas y sonoras aparece neutralizada en algunos de ellos.

${ }^{16}$ Ha de tenerse en cuenta que el mismo Rafael Cano diferencia "Cantabria, Vasconia, Castilla la Vieja" (Cano, 2004: 834). 
textos de la zona históricamente vascófona. Me refiero al seseo, al "trueque" entre los grafemas $\langle\mathrm{s}\rangle,\langle\mathrm{ss}\rangle,\langle$ ç $\rangle \mathrm{y}\langle\mathrm{z}\rangle$, que en los documentos históricos vascos, al igual que en textos andaluces (Alonso, 1955; Guitarte, 1983: \$6), se produce en dos direcciones: $\langle\mathrm{c}\rangle,\langle$ ç $\rangle,\langle\mathrm{z}\rangle \rightarrow\langle\mathrm{s}\rangle,\langle$ ss $\rangle \mathrm{y}\langle\mathrm{s}\rangle,\langle$ ss $\rangle \rightarrow\langle\mathrm{c}\rangle,\langle$ ç $\rangle,\langle\mathrm{z}\rangle$ (Isasi, Iribar y Túrrez, 2012: 175).

A pesar de que ha existido alguna duda, ${ }^{17}$ es comúnmente aceptado que las formas seseantes del castellano del territorio vasco no surgieron en los siglos XVI y XVII, sino a finales de la Edad Media: "Se comprueba la existencia continuada de testimonios seseantes de la zona vasca desde la Edad Media hasta el s. XVIII" (Iribar e Isasi, 2008: 256; véase, asimismo, Isasi, Iribar y Túrrez, 2012: 175). Es más: "El seseo se revela como la peculiaridad gráfica más significativa de estos documentos" (Iribar e Isasi, 2008: 256). De todas formas, parece que existieron diferencias diatópicas: Pedro de Madariaga, calígrafo vizcaíno de la segunda mitad del siglo XVI, describió el fenómeno para la zona catalana, pero no para la vasca: "en Valencia y Cataluña dizen hafer, dife, vefar, por hazer, dize, vezar" (1565: 101).

\subsubsection{Al investigar el origen del seseo vasco ha solido mencio-} narse la posible influencia del contacto entre las lenguas vasca y castellana: "concebido el seseo como una interferencia derivada del contacto con la lengua vasca, parece obligado ahondar en la relación del fenómeno con el propio sistema de sibilantes del euskera y en la relevancia que este pueda tener como clave para su comprensión histórica o presente" (Isasi, Iribar y Túrrez, 2012: 175). Aun así, no se ha determinado con claridad en qué dirección pudo producirse la supuesta influencia; es decir, si el seseo castellano fue provocado por la neutralización de las sibi-

\footnotetext{
${ }^{17}$ Cf. "no se puede negar con rotundidad que las cacografías vizcaínas puedan ser un mero reflejo de la variación del castellano en su tránsito al sistema consonántico moderno [...]. El argumento parece aplicable, en especial, a la inseguridad del escribano ante formas de aparición poco frecuente [...]. Pero no parece que este sea el caso de otros muchos testimonios" (Isasi, 2006: 534). Véanse asimismo las dudas expresadas anteriormente en Isasi (1999: 230-231).
} 
lantes vascas, si el proceso se produjo a la inversa o si se trató de un proceso bidireccional:

No parece sencillo determinar en cuál de las dos lenguas de esta comunidad bilingüe empezó la neutralización. ¿Encontramos seseo en el castellano de Micoleta por influencia del vascuence de Bilbao, donde se habían neutralizado las sibilantes con anterioridad o se neutralizan las sibilantes en dialecto vasco local porque el castellano usado en Bilbao había adoptado una norma seseante? (Hualde, 2010: 113).

A la hora de analizar la posible influencia del contacto lingüístico ha de tenerse en cuenta que en la zona vasca (y, sobre todo, fuera de las villas y ciudades) el castellano no estaba tan extendido como lo ha estado a posteriori ni geográficamente, ni socialmente: "it is the social context, not the structure of the languages involved, that determines the direction and the degree of interference" (Thomason y Kaufmann, 1988: 19). Tradicionalmente se ha aceptado que la influencia lingüística por contacto se produce con mayor facilidad en los núcleos urbanos más poblados, al resultar el contacto más intenso: “The more intense the contact situation is, the more likely it is that extensive structural borrowing will occur" (Thomason y Kaufmann, 1988: 67).

Respecto al área vasca, ha de recordarse que la crónica de los historiadores Juan Iñiguez Ibargüen y García Fernández de Cachopín (ca. 1558-1610) describe Bilbao como villa bilingüe (Arriolabengoa, 2008: 40). Por ello, la neutralización de las sibilantes vascas ha solido explicarse a través de la influencia castellana: "en esta parte occidental del país, el abandono de la distinción va de par con la romanización, y por ello, no parece fuera de lugar recordar aquí el seseo característico del castellano de Bilbao" (Michelena, 1968: 345). Asimismo, Hualde afirma: "Paradójicamente, el hecho de que la neutralización de punto de articulación en lengua vasca comience en la zona de Bilbao nos lleva a pensar en la influencia de la lengua castellana sobre la vasca en este sentido" (2010: 113).

La cuestión, de todas formas, parece requerir un análisis más amplio, ya que los últimos estudios realizados acerca del 
seseo vasco en textos castellanos han descrito el fenómeno también fuera de las áreas urbanas:

Hay seseo en todos los tres territorios [Álava, Bizkaia eta Gipuzkoa], por lo que la relación específica con las variantes dialectales de la lengua vasca puede ser condicionante de las realizaciones del seseo, pero no del origen del fenómeno, cuya relación con la presencia de la lengua vasca se revela más global. Es decir, en lo histórico, sesearon tanto los territorios que mantenían la distinción entre ese apical y la predorsal como aquellos otros que han evolucionado hacia su confusión, si bien es cierto que ha sido más fácil identificar ocurrencias seseantes en archivos vizcaínos y guipuzcoanos que se corresponden con áreas de mayor permanencia y vitalidad del euskera (Isasi, Iribar y Túrrez, 2012: 177).

A la luz de la afirmación precedente, el seseo castellano no se desarrolló por influencia de la neutralización ocurrida entre las sibilantes vascas, ya que el seseo también se documenta en los territorios en los que dichas sibilantes han mantenido la distinción sin neutralización alguna.

La cronología absoluta parece apuntar en la misma dirección: aunque en los primeros textos en euskera occidental (siglo XVI) se documenta la neutralización de las predorsales fricativas, la distinción es todavía mayoritaria y la pérdida de la misma se circunscribe casi exclusivamente a la posición ante oclusiva: parece, pues, que el proceso de expansión de la neutralización tanto entre las fricativas como entre las africadas se desarrolló durante los siglos XVII, XVIII y XIX. La expansión, además, parece haberse producido siguiendo un modelo jerárquico o de cascada: primero en los núcleos urbanos más importantes, para extenderse después a núcleos de menor densidad demográfica y mayor dispersión poblacional (Michelena, 1961: 231; Atutxa y Zuloaga, 2014).

Frente a tal cronología, ha de recordarse que el seseo en el castellano del área vasca se documenta desde finales de la Edad Media. 


\subsection{A modo de resumen: sobre el sistema de sibilantes castellano}

Las explicaciones precedentes son necesarias para conocer la complejidad de la situación y de los fenómenos lingüísticos estudiados. En resumen, si bien se trata de generalidades, los datos siguientes son aceptados comúnmente en la literatura sobre el tema bajo estudio:

- Algunas zonas del norte de la Península Ibérica (en concreto, áreas de Castilla la Vieja) fueron innovadoras en los procesos de cambio iniciados y desarrollados durante los siglos XVI, XVII y XVIII.

- Aunque el norte peninsular fue innovador, la cronología y la extensión de los cambios no fueron idénticos en todas las áreas: la cronología de algunos procesos y, sobre todo, la de la estabilización y generalización de la interdentalización, es tardía. ${ }^{18}$

- Respecto a la geografía lingüística, los límites del norte lingüístico peninsular no han sido establecidos y queda por estudiar qué lugar ocupaban las tierras vascas dentro de dicho norte lingüístico: carecemos de una descripción precisa de las áreas y filiaciones lingüísticas existentes durante los siglos pasados, y ni siquiera conocemos cuál era el ámbito geográfico exacto en el que convivían las lenguas vasca y castellana.

- En relación con lo anterior, no es sencillo determinar cuándo se iniciaron, desarrollaron y completaron los procesos de fricatización y ensordecimiento de las sibilantes castellanas; asimismo, es difícil determinar qué extensión ha tenido la realización $/ \theta /$ durante los últimos siglos en Bilbao.

- De cualquier modo, en primer lugar, ha de realizarse un estudio grafemático de cada fuente para pasar después a investigar la

18 "Gracias a A. Alonso sabemos que lo peregrino del timbre de la ç y la z españolas era una mezcla de siseo-ciceo. Esta mezcla de siseo y ciceo subsistió en Castilla y Toledo hasta muy avanzado el siglo xviI y sólo a finales de él o ya en el siglo XVIII se impuso la articulación ciceante pura $/ \theta /$. R. Lapesa utiliza para transcribir este sonido, mezcla del siseo y ciceo, el signo [ $\left.{ }_{\mathrm{s}}{ }_{\mathrm{s}}\right]$ " (Satorre, 1989: 286). 
relación entre los grafemas y la variación gráfica y el sistema fonológico subyacente que podría (o no) soportar dicha variación.

- Al trabajar con documentos del área vasca, ha de tenerse en cuenta el fenómeno del seseo, ya que aquellos hablantes que sesean no pronuncian la interdental $/ \theta /$ surgida de la necesidad de esquivar la homofonía tras las neutralizaciones ocurridas.

- En la zona meridional del País Vasco el seseo se documenta desde finales de la Edad Media y no parece que se trate de un fenómeno surgido por influencia de la neutralización en las series de sibilantes vascas, ya que el seseo castellano aparece también en territorios en los que la neutralización de sibilantes vascas no se ha producido. En términos de cronología absoluta, como se ha indicado, el seseo castellano es anterior a la neutralización de las fricativas vascas.

\section{El castellano de Micoleta: expresión gráfica de las sibilantes y sistema fonológico subyacente}

El objeto del presente apartado no es sino ofrecer una descripción fidedigna del sistema fonológico castellano y de las tendencias de cambio reflejadas en el manuscrito de Micoleta. Para dicha labor seguiré los criterios establecidos por Hualde (2010: $\$ 5.1)$ para el análisis del castellano documentado en un refranero bilingüe vasco-castellano de finales del siglo XVI. ${ }^{19}$

En concreto, en este apartado estudiaré la variación gráfica entre las sibilantes e intentaré determinar cuál era el sistema fonológico subyacente. Para la presente tarea he creído suficiente analizar la parte más extensa del texto de Micoleta, el diccionario vasco-castellano $(5 \mathrm{r}-9 \mathrm{v})$.

\footnotetext{
${ }^{19}$ Se trata de Refranes y sentencias comunes en bascuence, compilación anónima publicada por Pedro Porralis en Pamplona (Navarra) en 1596 y auténtica mina para el estudio, entre otros aspectos, del vasco occidental arcaico. Véase la excepcional edición crítica de Lakarra (1996).
} 


\subsection{Sobre las antiguas sibilantes africadas dentoalveolares}

4.1.1. Dentro de la oposición gráfica $\langle\mathrm{c}>\mathrm{y}\langle$ ç> vs $\langle\mathrm{z}\rangle$, la antigua africada dentoalveolar sorda /ts/ es expresada generalmente mediante $<c ̧>$ tanto en posición medial intervocálica como tras consonante sonante: $5 \mathrm{r}$ aguçar, $5 \mathrm{v}$ braço, 6r conoçer, $6 \mathrm{r}$ conoçimiento, 6r coraçon, 6r creçer, 6v difiçil, 6v emblanqueçer, $6 \mathrm{v}$ enloqueçer, 6v espaçio, 6v façil, 8r moço, 8r naçer, 8r naçido, 8r paçífico...; 5r adulçar, 5r alçar, 5v calçar, 5v calçones, 6v dulçe, 6r començar, 6v ençender, 6v ençerrar, 6v ençima, 6v ençino, $7 \mathrm{r}$ françes, $7 \mathrm{v}$ mançebo, 9r silençio, $7 \mathrm{v}$ março (sin embargo, $14 \mathrm{v}$ marzo), $7 \mathrm{v}$ merçed, $8 \mathrm{r}$ morçilla, 9v terçer, 9v torçer, etcétera.

Asimismo, $\langle\mathrm{c}\rangle$ no aparece en posición inicial para representar sibilante ante $\langle\mathrm{e}\rangle \mathrm{e}<\mathrm{i}>$, donde se emplea sistemáticamente $\langle$ ç>: 6r çebolla, 6r çer[r]ar, 6r çerro, 6r çevada, 6r çiego, $6 \mathrm{r}$ çielo, etcétera. En posiciones inicial e intervocálica $\langle\mathrm{c}\rangle$ representa la oclusiva velar sorda $/ \mathrm{k} /$ ante $\langle\mathrm{a}\rangle,\langle\mathrm{o}\rangle$ : 6r casa, 6r carne, 6r codo, 6r cuerno; 5r acompañar, 5v blancura, 6r clueca, $6 \mathrm{v}$ ducado, $7 \mathrm{v}$ loco, $8 \mathrm{v}$ pecado, etcétera. ${ }^{20}$

En algún caso aislado aparece $<\mathrm{c}>$ intervocálica (6v empecar, vea comencar) e incluso la misma raíz puede presentar variantes con $\langle\mathrm{c}\rangle \mathrm{y}$ ç $>$, como en $6 \mathrm{v}$ endurecer, pero $6 \mathrm{v}$ endureçerse. De todas formas, los ejemplos son muy escasos y bien podría tratarse de simples errores.

El manuscrito de Micoleta muestra, por lo tanto, que el autor optó por escribir $<c ̧>$ generalmente a inicio de palabra, en posición intervocálica y tras sonante porque reservó $<\mathrm{c}>$ para la oclusiva velar sorda (junto a $<\mathrm{qu}->$ en algunos casos).

Respecto a la oposición $\langle\mathrm{c}>\mathrm{y}<$ ç $>v s<\mathrm{z}>$, se registra $<\mathrm{z}>$ en contextos en los que etimológicamente existió una fricativa sorda, y se limitan casi en su totalidad a la posición intervocálica: ${ }^{21}$ 5r adelgazar, 5v caueza (pero también 5v \& 9r caveça y $13 \mathrm{v}$ cabecera), 9v tizon, 9v tozino, etcétera. Dentro de la muestra analizada existe una única $<\mathrm{z}->$ en posición inicial: aparece en la pala-

\footnotetext{
${ }^{20}$ También hallamos $<$ qu- $>$ ante $<\mathrm{e}>$ ( $8 \mathrm{v}$ quemar), $<\mathrm{i}>$ ( $8 \mathrm{v}$ quitar $),<8 \mathrm{v}>$ ( $8 \mathrm{v}$ quatro) y una vez ante $<0>$ en la variante latina $6 \mathrm{v}$ liquor.

${ }^{21}$ Dejo de lado arabismos como 5r azafrán y 5r azucar.
} 
bra 9v zorra y la <z-> inicial responde a la tradición ortográfica (Satorre, 1989: 275).

4.1.2. Si partimos del análisis de la representación de la antigua africada dentoalveolar sonora /dz/, veremos que en numerosas ocasiones aparece representada por $<\mathrm{Z}>$ en posición medial intervocálica y tras sonante, como en la época medieval: $5 \mathrm{v}$ avezes, $6 \mathrm{v}$ azeyte, 6r hazer, 6v deshazer, 6v doze, 7r granizo, $7 \mathrm{r}$ hezes, $9 \mathrm{r}$ rezar, 9v naturaleza, 9v vezino; 6r catorze, $8 \mathrm{r}$ onze, $8 \mathrm{v}$ quinze. En otros casos, sin embargo, como podía esperarse a la vista de lo descrito en el punto anterior, también hallamos $<c ̧>$ en ambas posiciones: $5 \mathrm{v}$ ançuelo; $5 \mathrm{v}$ bendeçir, $6 \mathrm{v}$ deçir, $6 \mathrm{v}$ doçientos, $7 \mathrm{r}$ coçina, etcétera.

En el punto anterior veíamos que $<\mathrm{z}->$ era inusual en posición inicial, y en este caso la situación se produce a la inversa: a pesar de los ejemplos hallados en posición medial, no he hallado ninguna $<-c>$ ni $<-c ̧>$ final. Los ejemplos de sibilantes a final de palabra no son demasiado abundantes en el apartado seleccionado para el análisis, pero presentan sistemáticamente la $\langle-\mathrm{z}\rangle$ tradicional: 6r vez, 6r diez, 7r luz, 7v lombriz, 8r nariz, 8v paz, etcétera. El carácter sordo o sonoro de las $<-z>$ finales fue motivo de discusión ya entre los autores clásicos que se ocuparon del tema (cf. Alonso, 1955: 158 y siguientes, Guitarte, 1983: 78 y siguientes), y en el corpus aquí analizado hay algún caso que podría llevarnos a pensar en una representación de la realización sonora mediante $\langle-\mathrm{z}\rangle$ : se trata de $v e z$ y sus derivados, que mantienen <-z-> intervocálica sistemáticamente (6r \& 8r \& 9v vez; $5 \mathrm{v} \& 6 \mathrm{r} \& 8 \mathrm{r} \&$ 9r vezes), si bien ha de tenerse en cuenta que las zetas finales no proceden de una única fuente y que en ocasiones se utilizó <-z> a pesar del carácter sordo de la consonante. Ese debió ser en el caso de palabras como coz y pez, documentadas tal cual en el manuscrito de Micoleta (6r y $8 \mathrm{v}$ respectivamente):

En alguna ocasión esta dental africada final no tenía este origen, sino que debería ser sorda por proceder de $\mathrm{C}$ agrupada con otra consonante: por ejemplo, PISCE > pez, CALCE > coz, etc. Sin embargo, la <-z> fue siempre la grafía utilizada para su representación gráfica (Satorre, 1989: 276). 
4.1.3. El análisis de los datos precedentes muestra que Micoleta empleó indistintamente $\langle c ̧>\mathrm{y}\langle\mathrm{z}>$ en posición intervocálica $\mathrm{y}$ tras sonante para representar las sibilantes africadas dentoalveolares sorda y sonora del castellano medieval. A la vista de ello, lo más pertinente es pensar que la diferenciación tampoco se producía en el habla local del autor; es decir, que la oposición entre africadas sordas y sonoras se había perdido con anterioridad. La afirmación no viene respaldada solamente por el uso indistinto de unos y otros grafemas en posiciones idénticas: han de tenerse en cuenta asimismo los casos en los que una misma palabra aparece con una y otra grafía (cf. $5 \mathrm{v}$ caueza, pero $9 \mathrm{r}$ caueça y $13 \mathrm{v}$ cabecera; el último, tomado de Minsheu).

Las únicas diferenciaciones gráficas de las antiguas africadas dentoalveolares se producen a inicio y final de palabra, donde Micoleta actuó reservando como norma general $<c ̧->$ para inicio y $<-z>$ para final. A la vista de ello, podría pensarse que la neutralización se había producido únicamente en las posiciones descritas, aunque se trata de una idea a desechar: "cualquier fonema consonántico castellano en posición final tiende a neutralizar la oposición sorda/sonora" (Satorre, 1989: 276, siguiendo a Alarcos, 1971: 184).

\subsection{Sobre las antiguas sibilantes fricativas dentoalveolares}

4.2.1. En el apartado de las fricativas apicoalveolares sordas y sonoras no he hallado casos en los que la $<-$ s- $>$ correspondiente a la antigua fricativa apicoalveolar sonora sustituya a la <-ss-> fricativa apicoalveolar sorda etimológica. Los ejemplos hallados muestran el dígrafo <-ss-> entre vocales: 5r abadessa, 5r amassar, $5 \mathrm{v}$ apriessa, $5 \mathrm{v}$ assentarse, $5 \mathrm{v}$ assador, $5 \mathrm{v}$ assí, $5 \mathrm{v}$ assomar, 5v assar, 7r gruesso, 7r passado, $7 \mathrm{r}$ huesso, 7v massa, $8 \mathrm{r}$ missa, 8r neçessaria, 8v passa, 8v passar, 8v passo, 9r siesso, etcétera. El hecho resulta llamativo en cierta medida, ya que la traducción castellana de los refranes recogidos en la obra Refranes y sentencias de $1596^{22}$ muestra varios ejemplos de <-s-> pro <-ss->: 32 pasado, 99 vasura, 173 pasito, 409 dieseys (apud Hualde, 2010:

${ }^{22}$ Aunque la obra fue impresa en Pamplona (Navarra), los refranes contenidos en 
102); sin embargo, parece que Micoleta se adhirió a un uso gráfico más conservador: $7 \mathrm{r}$ passado, $8 \mathrm{v}$ passar, $8 \mathrm{v}$ passo, etcétera.

Fuera del apartado de la obra de Micoleta tomado aquí como muestra, he hallado algún ejemplo de $<$ s $>$ pro $<$ ss $>$ en los diálogos tomados de Minsheu: cf. 13v aseo.

4.2.2. La antigua fricativa apicoalveolar sonora es generalmente expresada mediante <-s-> entre vocales; es decir, mantiene la grafía tradicional o antigua: $5 \mathrm{r} \cos a$, 6r casamiento, $7 \mathrm{r}$ hermosa, $7 \mathrm{r}$ huso, 7r husada, 7v losa, 7v mensagero, $7 \mathrm{v}$ mentiroso, $8 \mathrm{r}$ meson, $8 \mathrm{r}$ posada, $8 \mathrm{r}$ mesonero, $8 \mathrm{v}$ pesada, $8 \mathrm{v}$ pisar, $9 \mathrm{v}$ raposo, $9 \mathrm{v}$ seso, 9r trasera. Sin embargo, junto a la serie expuesta hay ejemplos en los que el dígrafo $<-$ ss- $>$ aparece en lugar de $<-s->$ : $6 \mathrm{r}$ cassarse, $8 \mathrm{v}$ pesso, $12 \mathrm{v}$ pessa, etcétera. Además, existen palabras que muestran ambas variantes: $6 \mathrm{r}$ casa, pero $12 \mathrm{v} \& 13 \mathrm{r} \&$ $13 \mathrm{v}$ - dos veces - \& 14r cassa; 6r casamiento, pero 6r cassarse; $7 \mathrm{v}$ mesa, pero $13 \mathrm{v}$ messa; $11 \mathrm{r}$ camisa, pero 6r camissa.

No he hallado trueques de $<$ ss $>$ por $<$ s $>$ fuera de la posición intervocálica.

4.2.3. Los datos recogidos en este segundo apartado muestran nuevamente dos tendencias. En primer lugar, el uso de $<$ ss $>$ por $<\mathrm{s}>$ revela la posibilidad de alternar ambos grafemas en posición intervocálica; el uso indistinto de $<-$ s- $>$ y $<-$ ss- $>$ en la misma palabra, además, no deja lugar a duda en torno a la equivalencia fonética de los mismos, por lo que nos hallamos nuevamente ante variantes puramente gráficas que reflejan la neutralización de las sibilantes fricativas apicoalveolares sordas y sonoras a favor de las primeras. En segundo lugar, el manuscrito vuelve a revelar un patrón ciertamente conservador: a pesar de las alternancias descritas y de la neutralización a favor de las fricativas sordas, la poligrafía se atestigua generalmente en la dirección $<$ ss $>\rightarrow<$ s $>$ y únicamente en posición intervocálica, al igual que en la serie de antiguas africadas dentoalveolares.

euskera muestran una variedad lingüística vizcaína del área de Bilbao (Lakarra, 1996; Zuloaga, 2011). 
Más allá del diccionario tomado como muestra en este trabajo, el análisis cuantitativo de algunas variantes de alta frecuencia viene a confirmar el estado avanzado de la neutralización sorda/sonora y la razón meramente gráfica de la existencia de algunas variantes. Tomando en consideración todo el manuscrito y en lo referido a las variantes decir dezir, he hallado veintinueve ejemplos de la serie decir, dice, etc., y quince ejemplos del patrón dezir. Por lo tanto, la frecuencia de uso de la variante antigua es menor en este caso (el 34\% de los ejemplos). Al contrario, analizando las variantes hacer hazer, la última (más antigua) es más frecuente: hay un único hace contra veinticuatro hazer. En este caso, por lo tanto, la variante moderna es totalmente minoritaria (el $4 \%$ de los ejemplos).

En el ámbito de las apicales, Micoleta actuó de forma prácticamente sistemática al utilizar la palabra cosa: aparecen sesenta y tres ejemplos de $\cos a(s)$, no hay ningún ejemplo de cossa(s) y documenta un único ejemplo de coza, que indicaría seseo $(\$ 4.3 .2)$.

4.2.4. A la vista de los resultados tras el análisis de las variantes gráficas correspondientes a las antiguas africadas dentoalveolares y fricativas apicoalveolares sordas y sonoras, hallamos en el manuscrito de Micoleta usos y tendencias interesantes desde el punto de vista gráfico y fonético-fonológico. Por un lado, los datos analizados permiten afirmar que el autor siguió ciertas normas gráficas: inexistencia o existencia escasa de algunos grafemas en ciertas posiciones o palabras, unidireccionalidad en algunos trueques, etcétera. Por otro lado, la variación gráfica deja interesantes resquicios a través de los cuales se pueden apreciar cambios que corresponden al plano fónico.

\subsection{El seseo en el manuscrito de Micoleta}

4.3.1. Junto a los cambios más o menos generales que conformaron la transición entre los sistemas fonológicos medieval y moderno en castellano, algunas innovaciones ocurridas en ciertas áreas cobran especial interés, ya que muestran patrones 
divergentes y sirven para caracterizar y diferenciar variedades lingüísticas. Por lo que respecta al estudio del castellano del País Vasco, el estudio del seseo es imprescindible:

El término seseo se refiere en este caso a la indistinción de los resultados de las antiguas predorsales africadas medievales y de las apicoalveolares, en un proceso que pudo ser en un principio çeçeante - en sentido lapesiano- para sus primeras etapas documentadas, aunque, en sincronía con la evolución del sistema consonántico castellano, la reducción desembocara en un seseo, cuyas realizaciones podemos ahora comprender mejor a la luz de sus posibles paralelismos en el actual (Isasi, Iribar y Túrrez, 2012: 175).

4.3.2. En la práctica, por lo tanto, los textos vascos que reflejan gráficamente el seseo lo hacen, como se ha indicado anteriormente (\$3.2), mediante la utilización de $\langle$ s $>$ y $<$ ss $>$ en lugar de $\langle$ c $>,\langle$ ç $>$ y $\langle$ z $>$ o de $\langle$ c $>,\langle$ ç $\rangle$ y $\langle$ z $>$ en lugar de $\langle$ s $>$ y $\langle$ ss $>$. Es usual que una misma fuente presente ambas opciones, $y$ tal es el caso del manuscrito de Micoleta.

En primer lugar, entre los casos de seseo a favor de $<\mathrm{s}>\mathrm{y}$ $<$ ss $>$ he hallado tres variantes de la palabra vascuence tras sonante: $12 \mathrm{r}$ vascuence y $6 \mathrm{r} \& 9 \mathrm{v} \& 10 \mathrm{v}$ (en dos ocasiones) vascuenze por un lado, y $3 \mathrm{r}$ vascuense, $4 \mathrm{v}$ vascuensean y $10 \mathrm{v}$ vascuenses por otro. Los siguientes ejemplos corresponden a la posición medial intervocálica, donde el grafema más usual es $\langle\mathrm{s}\rangle$ : $5 \mathrm{r}$ alcusa 'alcuza', 6r coser 'cocer', 6v (en dos ocasiones) envejeserse, $7 \mathrm{r}$ peses 'peces', 7v longanisa, $8 \mathrm{r}$ pescueso 'pescuezo', 9v vasiar 'vaciar', 9v vasia 'vacía. Con $<$ ss $>$ aparece $7 \mathrm{v}$ messer 'mecer'. En algún caso más allá del apartado del manuscrito aquí estudiado, la misma palabra muestra distintas grafías: cf. 14r tasa 'taza', pero $14 \mathrm{r}$ taza y 14 r tazas en el apartado de los diálogos tomados de Minsheu.

En segundo lugar, entre los casos de seseo a favor de $\langle c\rangle$, $<$ ç $>\mathrm{y}\langle\mathrm{z}>$ en ocasiones aparece $\langle\mathrm{z}>$ en posición implosiva: $5 \mathrm{v}$ boztezo, $7 \mathrm{r} \& 7 \mathrm{v}$ (en cuatro ocasiones) mez y 9v toz. ${ }^{23}$ En posición intervocálica aparecen indistintamente $<c ̧>$ y $<\mathrm{z}>$ : $5 \mathrm{r}$

${ }^{23}$ Fuera del diccionario analizado como muestra hay cinco ejemplos de vazccorrespondientes a las palabras vascuence y vascongada. 
abraçar 'abrasar' (aunque inmediatamente después se escriba $5 \mathrm{r}$ cosa abrasada), 7r graza, 7r graça, 8r coza y 12v brazero 'brasero' Hay, por otro lado, un caso de $<\mathrm{c}>$ por $<$ s $>$ en posición inicial: 6r cidra, bebida 'sidra'.

4.3.3. Los ejemplos precedentes muestran una igualación entre los grafemas etimológicamente correspondientes a las sibilantes dentoalveolares y apicoalveolares en castellano; en concreto, a pesar de la escasez de ejemplos, se registra una tendencia a favor de $\langle$ ç $>$ y $<\mathrm{z}>$ en posición implosiva, y a favor de $<$ s $>$ tras sonante y en posición intervocálica. Además, la existencia de pares del tipo 14r tasa 14r taza o 5r abraçar 5r abrasada (cf. también $12 \mathrm{v}$ brazero) y la indistinción en ejemplos como 6r coser ('cocer' pero igualmente 'unir con un hilo') no dejan lugar a duda en torno a la existencia del seseo. El último ejemplo resulta especialmente interesante, ya que el autor creyó necesario intentar diferenciar uno y otro verbo, aunque no lo hizo gráficamente, sino añadiendo una nueva palabra que ayuda a aclarar la acepción: 6r coser 'cocer', pero 6r coser, lienço, etcétera.

4.3.4. Aplicando en este apartado la misma lógica argumentativa que en los precedentes, se observa que el autor utiliza indistintamente unos y otros grafemas, documentando variantes seseantes, como por otra parte podría esperarse a la luz de testimonios anteriores y posteriores del mismo territorio. La variación se enmarca, por lo tanto, no en un uso anárquico por parte del autor, como llegó a proponerse para los testimonios de seseo bidireccionales andaluces por Alonso (1955), sino dentro de la tensión existente dentro de "la convivencia de la norma distinguidora de base castellana con el uso confundidor local" (Guitarte, 1983: 83). Precisamente, creo que el argumentario esgrimido por Guitarte para explicar la variación de los testimonios andaluces es perfectamente aplicable a la situación reflejada en el texto de Micoleta, y que el uso de $<\mathrm{z}>,\langle\mathrm{c}\rangle \mathrm{y}<$ ç $>$ pro $<$ s $>$ y $<$ ss $>$ responde a la ultracorrección:

Como existían previamente tres sibilantes: dental, alveolar y palatal, la pérdida de la oposición entre dentales y alveolares hizo que al 
fonema palatal se opusiera desde entonces un solo fonema; la distinción entre las sibilantes fue de "palatal-no palatal". Esta última podía realizarse en una zona que iba de los dientes a los alvéolos, pues esto significa decir que ya no era distintiva la localización que antes se hacía en esta región. Por tanto, si había un solo fonema sibilante no palatal, es absurdo pensar que se realizaba con distinciones de localización dental y alveolar (aunque "se aplicaran mal"): esto equivale a sostener que se distinguía lo que no se distinguía (Guitarte, 1983: 90).

A la luz de lo anterior, no creo que haya que pensar en una confusión surgida de la proximidad entre los puntos de articulación de las fricativas castellanas; no creo que deba pensarse en el reflejo gráfico y desordenado de realizaciones fonéticas distintas. ${ }^{24}$ Más bien muestran un intento por parte del autor de no exponer por escrito una característica del habla local siguiendo una norma gráfica diferenciadora, intento que, por otra parte, conduce al autor a la poligrafía en la misma palabra y a caer en casos de ultracorrección. Micoleta intentó, por lo tanto, adscribirse a una norma que debía percibir como más correcta, formal o prestigiosa, ${ }^{25}$ si bien no lo logró con sistematicidad, como es habitual en estos casos:

Los documentos no son una copia fiel de la lengua oral, en los que automáticamente emerjan las características de una determinada

\footnotetext{
${ }^{24}$ Es cierto que el seseo vasco puede realizarse hoy en día a través de dos soluciones, una apicoalveolar y una predorsal (Isasi, Iribar y Moral del Hoyo, 2009: 233); sin embargo, existe un patrón geográfico general para cada una de ellas: hallamos la primera entre los hablantes vizcaínos tanto cuando hablan en euskera como cuando sesean en castellano, y la segunda en hablantes de variantes vascas que han mantenido la distinción entre dental y alveolar.

${ }^{25}$ Llegados a este punto, debería estudiarse en qué medida pueden aplicarse las características atribuidas en los textos literarios españoles al "habla vizcaína" (cf. Etxague, 2012) según los estratos sociales de cada época y la formalidad de la documentación analizada. Desconozco trabajo alguno que aborde el seseo desde el punto de vista de la sociolingüística histórica, pero parece que se trata de una característica atribuida a los estratos sociales más bajos, por lo que es razonable pensar que los miembros de la alta sociedad aprendieron y reflejaron antes que los de los estratos inferiores a pronunciar $/ \theta /$.
} 
lengua, pero, aún con este contratiempo, es posible detectar algunas variaciones gráficas que pueden estar relacionadas con la identificación de rasgos particulares de la lengua que se trasluce a través de la escritura (Oyosa, 2013: 305).

\section{Conclusiones}

5.1. El manuscrito de Micoleta fue redactado en el período de transición entre el castellano medieval y el moderno; es decir, en una época lingüística en la que se consumaron algunos cambios iniciados siglos atrás y en la que otros se estaban desarrollando.

5.2. Por lo que respecta al castellano de Micoleta, no observamos en el bilbaíno a un autor descuidado o anárquico, como se ha llegado a afirmar. El sistema utilizado para redactar su Modo breve... refleja conocimientos de una o varias tradiciones gráficas pertenecientes a un modelo conservador, hecho nada extraño, por otra parte, dentro del ámbito gráfico y escrito: “Una grafía puede distinguir artificialmente lo que en la pronunciación es igual, o bien se ha nivelado. Una distinción gráfica no indica forzosamente la existencia de una diferencia fonética" (Pensado, 1983: 25).

En el caso del manuscrito aquí estudiado, se aprecian usos gráficos sistemáticos que reflejan criterios y decisiones establecidas de antemano: entre las antiguas dentoalveolares el grafema $<c>$ se reserva generalmente para la oclusiva velar sorda diferenciándose de $\langle c ̧>$, que expresa el sibilante. Asimismo, apenas hay una $\langle$ z- $>$ inicial y no se registran casos de $\langle-$ c $>$ y $<-c ̧>$ en posición final.

Entre las apicoalveolares no he hallado $<\mathrm{s}>$ pro $<\mathrm{ss}>$, aunque textos más antiguos de la misma zona (y los diálogos tomados por el mismo Micoleta del trabajo de Minsheu) documenten el cambio. La dirección es $<$ ss $>$ pro $<$ s $>$ en Micoleta, y se produce únicamente en posición intervocálica: no he hallado $<$ ss-> inicial ni <-ss $>$ final.

Junto a las normas gráficas establecidas por el autor y descritas en los párrafos y apartados precedentes, hay numerosos 
casos en posición medial intervocálica y tras sonante en los que no se mantienen las antiguas distinciones $\langle\mathrm{c}\rangle \mathrm{y}\langle$ ç $\rangle$ vs $\langle\mathrm{z}\rangle \mathrm{y}$ $<\mathrm{s}>v s<\mathrm{ss}>$. Precisamente, la abundancia de ejemplos (aunque se produzcan generalmente de forma unidireccional) en los que unos y otros grafemas pueden utilizarse indistintamente (en ocasiones, incluso en la misma palabra) refleja que la oposición entre sordas y sonoras estaba neutralizada para mediados del siglo XVII en Bilbao. Asimismo, el análisis cuantitativo de las variantes decir dezir y hacer hazer muestra patrones contrapuestos que no se explican si no es a través de una neutralización reflejada claramente en un caso y de un uso gráfico conservador en el otro.

5.3. En cuanto al seseo, vuelve a resultar característico de los textos castellanos del territorio vascohablante, y se documenta, como se ha indicado, en dos direcciones: (a) $\langle\mathrm{c}\rangle,\langle\mathrm{c}\rangle,\langle\mathrm{Z}\rangle \rightarrow$ $\langle$ s $>,\langle$ ss $>$ y (b) $\langle$ s $\rangle,\langle$ ss $\rangle \rightarrow\langle$ c $\rangle,\langle$ ç $\rangle,\langle$ z $\rangle$.

El caso (a) reflejaría una pronunciación propiamente seseante, y el (b) está formado por variantes puramente gráficas surgidas de ultracorrecciones realizadas por el autor. Se trata, al fin y al cabo, de emplear los mismos argumentos esgrimidos en el análisis de la representación de las antiguas predorsales y apicoalveolares: el autor pretendió adscribirse a una norma más general y prestigiosa, aunque no lo logró completamente y el texto deja entrever el seseo característico de su lengua local.

El hecho de intentar corregir (o, directamente, hipercorregir) los casos de seseo podrían revelar, además, el escaso prestigio que debía tener dicha pronunciación al menos en algunos estratos sociales y en el ámbito de la escritura.

5.4. Me detendré en este último apartado a analizar la posible existencia de la $/ \theta /$ interdental en el Bilbao de $\sim 1650$. Los procesos (fricatización y ensordecimiento) que provocaron el adelantamiento del punto de articulación para evitar homofonía se hallaban consumados en la época en la que Micoleta redactó su Modo breve, y así se refleja en el texto; por lo tanto, "los requisitos" que precedieron a la interdentalización en algunas hablas se cumplían a mediados del siglo Xviı en Bilbao. En vista de ello, 
podría pensarse, como Ulibarri (2015), que la / $\theta$ / interdental se había creado y extendido lo suficiente como para reservarle los grafemas $\langle\mathrm{c}\rangle,\langle\mathrm{c}\rangle \mathrm{y}\langle\mathrm{z}\rangle$, hecho que explicaría el uso indiscriminado de $<s>$ para expresar cualquier sibilante vasca. Sin salir del ámbito castellano, sin embargo, dicho punto de vista halla un obstáculo, ya que junto a las neutralizaciones consumadas descritas anteriormente Micoleta también documenta de forma clara un rasgo a tener en cuenta necesariamente: el seseo. Ha de tomarse en consideración, pues, que aquellos hablantes que sesean no interdentalizan. Precisamente, el manuscrito documenta diversos casos de $\langle\mathrm{s}>\mathrm{y}<\mathrm{ss}>$ pro $\langle\mathrm{c}>$, $\langle$ ç $>$ o $<\mathrm{z}>$ que, en ocasiones, ocurren en la misma palabra. Además, los casos de hipercorrección suponen un problema para la hipótesis de Ulibarri (2015), según la cual $\langle\mathrm{c}\rangle,\langle c ̧>\mathrm{y}\langle\mathrm{z}\rangle$ se reservarían para la interdental: no parece que ejemplos como 5v boztezo, 6r graza, 6r cidra, 8r coza o 9v toz, por citar algunos, ayuden en esa dirección. $^{26}$

Desde mi punto de vista, no existen argumentos gráficos suficientes como para pensar en una $/ \theta$ / extendida para la que se reservaron ciertos grafemas: es cierto que para la época tampoco tendría por qué esperarse una expresión gráfica unívoca y sistemática de la misma; sin embargo, la existencia del seseo y de la utilización indistinta de grafemas como $\langle$ ç $\rangle,\langle\mathrm{z}\rangle \mathrm{y}\langle\mathrm{s}\rangle$ en las mismas posiciones (y en las mismas palabras) me llevan a pensar más en un seseo extendido en el habla local y a retomar las palabras de Guitarte: "La distinción entre las sibilantes fue de palatal / no palatal” (1983: 90), donde la no palatal no sería interdental sino alveolar sorda.

Deberíamos pensar que Micoleta utilizó por escrito una distinción no sistemática pero abundante correspondiente al ámbito gráfico y escrito. El bilbaíno no transcribió (por supuesto, no cabe esperar que lo hiciese) los rasgos del habla local, sino que se adscribió a las normas y tradiciones gráficas que debió aprender y sistematizar en cierta medida: "La población más

\footnotetext{
${ }^{26}$ Tampoco ayudarían, en efecto, los casos de hipercorrección en vasco, donde se lee eroçi (etim. erosi), suritaçuna (etim. zuritasuna), maztia (etim. mahastia), ynez eguin (etim. ihes egin), etcétera.
} 
selecta y cultivada utilizaría una norma lingüística mucho más inmovilista y tradicional" (Satorre, 1989: 272). Deberíamos contraponer, por lo tanto, la posición sociocultural del autor y los usos escritos derivados de la misma a los usos cotidianos de los hablantes locales, y explicar así el sistema gráfico de Micoleta como un sistema de corte generalmente conservador en el que se filtran reflejos del habla local del entorno del autor.

\section{Bibliografía}

Alarcos, E. (1971), Fonología española, Madrid, Espasa-Calpe. Alonso, A. (1955), De la pronunciación medieval a la moderna en español, Madrid, Gredos.

Ariza, M. (1994), Sobre fonética histórica del español, Madrid, Arco/Libros.

ArriolabengoA, J. (2008), Euskara Ibarguen-Cachopín kronikan (XVI. mendea), Bilbao, Euskaltzaindia.

Atutxa, U. (2013), “Txistukarien neutralizazioa mendebaldeko euskaran XVI-XVIII. mendeen bitartean (lehen hurbilketa)", en R. Gómez, J. Gorrochategui, J. A. Lakarra y C. Mounole (eds.), Actas del Tercer Congreso de la Cátedra Koldo Mitxelena, Vitoria-Gasteiz, Universidad del País Vasco, pp. 61-75.

Atutxa, U. y E. Zuloaga (2014), "La neutralización de las sibilantes en vasco: una perspectiva diacrónica”, en F. Jiménez, A. Jimeno, A. de Lucas y N. Celayeta (eds.), Variación geográfica y social en el panorama lingüístico español, Pamplona, Servicio de Publicaciones de la Universidad de Navarra, pp. 21-32.

Bizcarrondo, G. (2002), "Romance en Bilbao durante el siglo XVII: Modo breve de aprender la lengua vizcayna de R. de Micoleta”, en A. Arejita, A. Elejabeitia, C. Isasi y J. Otaegi (eds.), Bilbao. El espacio lingüístico. Simposio 700 aniversario, Bilbao, Universidad de Deusto, pp. 219-237.

Blanco, M. (2006), Aproximación a la cronología de las transformaciones funcionales de labiales y sibilantes del español, Santiago, Universidade de Santiago de Compostela. 
Cabrera, C. (2003), "Reflexiones sobre grafemática histórica. Usos y mecanismos grafémicos en los documentos romances peninsulares", en J. Borrego, J. Fernández, L. Santos y R. Senabre (eds.), Cuestiones de actualidad en lengua española, Salamanca, Universidad de Salamanca, pp. 161-170.

Cano, R. (2004), "Cambios en la fonología del español durante los siglos XVI y XVII", en R. Cano (coord.), Historia de la lengua española, Madrid, Ariel, pp. 825-858.

Cid, J. A. (1997), Diálogos. John Minsheu. Edición crítica on line, Centro Virtual Cervantes, Madrid. <https://cvc.cervantes. es/literatura/clasicos/dialogos_minsheu/default.htm>

Dodgson, E. S. (1897), Modo Breve de aprender la lengua Vizcayna. Compuesto por el l. ${ }^{\text {do }}$ Rafael Micoleta, presbyt. ${ }^{\circ}$ de la muy leal y noble Villa de Bilbao. 1653, Sevilla, F. de P. Díaz.

Dodgson, E. S. (1908), "Sir Thomas Browne and Rafael Nicoleta", The Academy, 2, p. 8.

Egurtzegi, A. (2013), "Phonetics and Phonology", en M. Martínez-Areta (ed.), Basque and Proto-Basque, Fráncfort, Peter Lang, pp. 119-172.

Etxague, J. (2012), "El trasfondo lingüístico y cultural del 'habla vizcaína', en B. Camus y S. Gómez Seibane (eds.), El castellano del País Vasco, Bilbao, Universidad del País Vasco, pp. 21-43.

Frago, J. A. (1977), "Para la historia de la velarización española”, Archivum, XXVIII, pp. 219-225.

Frago, J. A. (1981), "Nueva contribución a la historia del reajuste fonológico español moderno", Cuadernos de Filología, II Studia linguistica hispanica: 2, pp. 53-74.

Frago, J. A. (1985), "De los fonemas medievales /ŝ, $\hat{z} /$ al interdental fricativo $/ \theta /$ delespañol moderno", en Philologica Hispaniensia in honorem Manuel Alvar, v. 2, Madrid, Gredos, pp. 205-216.

Guitarte, G. (1983), "Las supuestas tres etapas del seseo", en Siete estudios sobre el español de América, México, Universidad Nacional Autónoma de México, pp. 63-98.

Guitarte, G. (1992a), “Cecear y palabras afines”, en M. Ariza, R. Cano, J. M. Mendoza y A. Narbona (eds.), Actas del II 
Congreso Internacional de historia de la lengua española (Sevilla, 1990), Madrid, Pabellón de España, pp. 127-164. Guitarte, G. (1992b), "La teoría de la ç como mezcla de siseo y ciceo", en E. Luna (coord.), Scripta Philologica in honorem M. Lope Blanch, México, Universidad Nacional Autónoma México, pp. 285-328.

HuAlde, J. I. (2000), “Bizkaiko kostaldeko hizkerak atzo, gaur eta bihar", en K. Zuazo (ed.), Dialektologia gaiak, VitoriaGasteiz, Diputación Foral de Álava, pp. 13-28.

Hualde, J. I. (2010), “Neutralización de sibilantes vascas y seseo en castellano", Oihenart, 25, pp. 89-116.

Igartua, I. y X. Zabalza (2012), Breve historia de la lengua vasca, Donostia/San Sebastián, Instituto Vasco Etxepare.

Iribar Ibabe, A. y C. Isasi Martínez (2008), "El seseo vasco: nuevos datos para una vieja cuestión", Oihenart, 23, pp. 241-258.

Isasi Martínez, C. (1999), “Seseo, 'ese’ sigmática y edición de textos vascos", Fontes Linguae Vasconum, 31:81, pp. 227240.

Isasi Martínez, C. (2006), “A vueltas con el seseo y otras cuestiones de fonética y morfología en documentación vizcaína”, en J. A. Lakarra y J. I. Hualde (eds.), Studies in Basque and Historical Linguistics in Memory of R. L. Trask (ASJU 40, 1/2), Donostia/San Sebastián y Bilbao, Diputación Foral de Gipuzkoa y Universidad del País Vasco, pp. 531546.

Isasi, C., A. Iribar e I. Túrrez (2012), "Seseo vasco. Nuevos aportes”, en B. Camus y S. Gómez (eds.), El castellano del País Vasco, Bilbao, Universidad del País Vasco, pp. 173-190.

Isasi, C., A. Iribar y C. Moral Del Hoyo (2009), "Una transferencia vasca: el seseo de hablantes vizcaínos y guipuzcoanos", Oihenart, 24, pp. 201-235.

LAKARRA, J. A. (1985), "Literatur gipuzkerarantz. Larramendiren Azkoitiko sermoia”, Anuario del Seminario de Filología Vasca Julio de Urquijo, 19:1, pp. 235-281.

LAKARRA, J. A. (1996), Refranes y sentencias (1596). Edizioa eta ikerketak, Bilbao, Euskaltzaindia. 
Larramendi, M. (1728), El impossible vencido. Arte de la lengua bascongada. Salamanca, Antonio Joseph Villagordo.

Larramendi, M. (1745), Diccionario Trilingüe del Castellano, Bascuence y Latín, Donostia / San Sebastián, Bartholome Riesgo y Montero.

LíbANO, A. (1998), "Diacronía de las alternancias gráficas navarro-aragonesas: las sibilantes medievales", en J. M. Blecua, J. Gutiérrez y L. Sala (eds.), Estudios de grafemática en el dominio hispano, Salamanca, Universidad de Salamanca, pp. 135-148.

Madariaga, P. (1565), Libro subtilissimo intitulado Honra de Escriuanos, Valencia, Iuan de Mey.

Malkiel, Y. (1971), "Derivational Transparency as an Occasional Co-Determinant of Sound Change. A New Causal Ingredient in the Distribution of -ç- and - $\mathrm{Z}$ - in Ancient Hispano-Romance", Romance Philology, XXV:1, pp. 1-52.

MichelenA, L. (1957), "Las antiguas consonantes vascas", en J. A. Lakarra e I. Ruiz, (eds.), Luis Michelena. Obras completas, VII, Donostia / San Sebastián / Vitoria-Gasteiz, Universidad del País Vasco / Diputación Foral de Guipúzcoa, 2011, pp. 57-91.

Michelena, L. (1961), Fonética histórica vasca, reimpreso en J. A. Lakarra e I. Ruiz, (eds.), Luis Michelena. Obras completas, VI, Donostia / San Sebastián / Vitoria-Gasteiz, Universidad del País Vasco / Diputación Foral de Guipúzcoa, 2011, pp. 1-543.

MichelenA, L. (1964), Textos arcaicos vascos, reimpreso en A. Lakarra e I. Ruiz, (eds.), Luis Michelena. Obras completas, VI, Donostia / San Sebastián / Vitoria-Gasteiz, Universidad del País Vasco / Diputación Foral de Guipúzcoa, 2011, pp. 1-197.

Michelena, L. (1968), "Lat. s: el testimonio vasco”, J. A. Lakarra e I. Ruiz, (eds.), Luis Michelena. Obras completas, I, Donostia / San Sebastián / Vitoria-Gasteiz, Universidad del País Vasco / Diputación Foral de Guipúzcoa, 2011, pp. 343-358. MujıKA, J.A. (2002), Euskal ortografiaren hastapenak Iparraldeko literaturan, Bilbao, Universidad del País Vasco. 
Oyosa, A. E. (2007), “Representación gráfica de las sibilantes en el siglo Xvi: diferentes normas gráficas”, Anuario de Letras, XLV, pp. 25-51.

Oyosa, A. E. (2013), “Consideraciones sobre grafemática en el ámbito hispánico”, Anuario de Letras. Lingüística y Filología, 1, 273-348.

Pagola, R. M. (2002), "Bilboko euskara XVII. mendean: Micoletaren euskaraz ikasteko metodoa”, en A. Arejita, A. Elejabeitia, C. Isasi y J. Otaegi (eds.), Bilbao. El espacio lingüístico. Simposio 700 aniversario, Bilbao, Universidad de Deusto, pp. 201-218.

Pensado, C. (1983), El orden histórico de los procesos fonológicos, Salamanca, Caja de Ahorros y M. P. de Salamanca.

Pikabea, J. (1993), Lapurtera idatzia (XVII-XIX). Bilakaera baten urratsak, Donostia / San Sebastián, Fundación Kutxa.

SANPERE I MiQuel, S. (1880), "Modo breve para aprender la lengua vizcayna. Compuesto por el doctor Rafael Micoleta, presbítero de la M. L. y N. villa de Bilbao. 1653", Revista de ciencias históricas, 2, pp. 122-156.

Sarasola, I. (1983), "Contribución al estudio y edición de textos arcaicos vascos", Anuario del Seminario de Filología Vasca Julio de Urquijo (ASJU), 17:1, pp. 69-212.

SAtorre, F. J. (1989), “c, ç y z en la zona de Valladolid en el paso del siglo xvi al Xviı", Anuario de Estudios Filológicos, 12, pp. 267-290.

Thomason, S. G. y Kaufmann, T. (1988), Language Contact, Creolization and Genetic Linguistics, Los Angeles, University of California Press.

Trask, R. L. (1997), The History of Basque, Londres, Routledge. UlibARRI, K. (2015), Dotrinazko sermoitegia: galduriko hizkerak eta dialektologia historikoa, Tesis doctoral inédita, Universidad del País Vasco (UPV/EHU).

URGELL, B. (2005), "Larramendiren euskal liburuak 1745 arte: testu bibliografiaranzko hurbilketa bat", Lapurdum, 10, pp. 247-286.

Zelaieta, A. (1988), "Rafael Micoleta Çamudio: Modo breue de 
aprender la lengua vizcayna", Hizkuntza eta literatura, 7, pp. 133-214.

Zelaieta, A. (1995), Rafael Mikoletaren era llaburra. Bilbao, AEK.

ZuloAgA, E. (2011), "Bizkaiko jauntxoen inguruko herri-literaturaz", Anuario del Seminario de Filología Vasca Julio de Urquijo, 45:2, pp. 53-69.

\section{ENEKO ZULOAGA}

Cursó Filología Vasca en la Universidad de Deusto (Bilbao, 2003-2007) y el máster de Lingüística y Filología Vasca en la Facultad de Letras de la Universidad del País Vasco (VitoriaGasteiz, 2010), donde ultima su tesis doctoral en el departamento de Lingüística y Estudios Vascos. A lo largo de la última década ha trabajado en el ámbito de la dialectología y la sociolingüística, y hoy en día es profesor-investigador a tiempo completo en la Facultad de Educación de Bilbao, en la Universidad del País Vasco (UPv/EHU). Sus líneas de investigación son la lingüística histórica, la filología y la dialectología diacrónica. 